\title{
Buprenorphine - an attractive opioid with underutilized potential in treatment of chronic pain
}

This article was published in the following Dove Press journal: Journal of Pain Research

4 December 2015

Number of times this article has been viewed

\author{
Ish K Khanna \\ Sivaram Pillarisetti \\ NeuroPn Therapeutics, Alpharetta, \\ GA, USA
}

\begin{abstract}
Despite proven clinical utility, buprenorphine has not been used widely for the treatment of chronic pain. Questions about "ceiling effect" or bell-shaped curve observed for analgesia in preclinical studies and potential withdrawal issues on combining with marketed $\mu$-agonists continue to hinder progress in expanding full potential of buprenorphine in the treatment of cancer and noncancer pain. Mounting evidence from clinical studies and conclusions drawn by a panel of experts strongly support superior safety and efficacy profile of buprenorphine vs marketed opioids. No ceiling on analgesic effect has been reported in clinical studies. The receptor pharmacology and pharmacokinetics profile of buprenorphine is complex but unique and contributes to its distinct safety and efficacy. The buprenorphine pharmacology also allows it to be combined with other $\mu$-receptor opioids for additivity in efficacy. Transdermal delivery products of buprenorphine have been preferred choices for the management of pain but new delivery options are under investigation for the treatment of both opioid dependence and chronic pain.
\end{abstract}

Keywords: buprenorphine, opioids, opioid dependence, partial agonist, hyperalgesia, neuropathic pain

\section{Introduction}

Opioids are the market leaders for treatment of moderate to severe chronic pain among adults, amounting to over $\$ 10$ billion in global sales. The opioids are emerging as the primary option for cancer pain treatment as approximately $70 \%$ of cancer patients and $85 \%$ of those suffering from cancer-related pain eventually require management with opioids. ${ }^{1,2}$ The use of opioids is also increasing for treatment of chronic nonmalignant pain with established benefits in inflammatory, ischemic, visceral, musculoskeletal, and neuropathic pain. ${ }^{3,4}$ Despite rising opioid prescriptions (11.8\% in 2010 in US), many patients feel nonsatisfactory response to treatment options. ${ }^{5}$ In addition, long-term use of opioid therapy leads to the development of tolerance and hyperalgesia limiting their clinical utility in controlling chronic pain. Chronic use of opioids also accounts for other side effects such as respiratory depression, constipation, dependence, and abuse potential. With a growing senior population (projected to be approximately $25 \%$ by 2020 in major markets), there is constant demand for more efficacious and safer treatment options for patients.

\section{Structure and pharmacology}

Buprenorphine (Figure 1A) is a semi synthetic derivative of an opiate alkaloid thebaine that is isolated from the poppy Papaver somniferum. Buprenorphine is a hydrophobic 
A

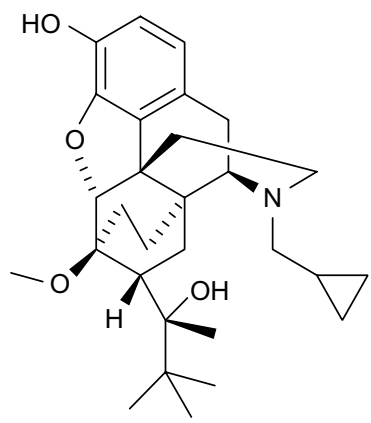

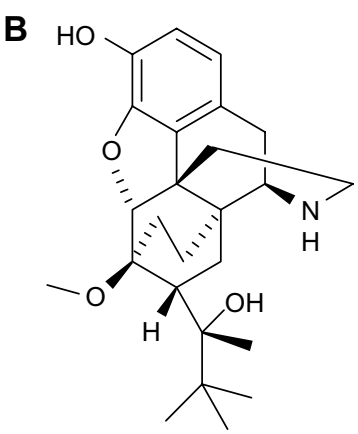

Figure I Structures of buprenorphine (A) and norbuprenorphine (B).

molecule and carries a complex chemical structure with multiple chiral centers. Buprenorphine was introduced in the early 1980s as an opioid analgesic in Europe and subsequently for the treatment of opioid addiction in France in 1996. It is available in the US for the treatment of opioid addiction maintenance programs, and for the treatment of chronic pain.

\section{Interactions with opioid receptors (ORs)}

Buprenorphine has a distinct profile, significantly different from morphine, codeine, fentanyl, or methadone. It is a potent but partial agonist of $\mu$-opioid receptor ( $\mu$-OR), showing a high affinity but low intrinsic activity (Figure 2). High potency and slow off rate (half-life of association/dissociation is $2-5$ hours $)^{6}$ help buprenorphine displace other $\mu$-agonists such as morphine, methadone from receptors and overcome opioid dependence issues. Buprenorphine is approximately $25-100$ times more potent than morphine.
The slow dissociation from $\mu$-receptor also accounts for its prolonged therapeutic effect to treat opioid dependence as well as pain.

The in vitro profile of buprenorphine against ORs is captured in Table 1. ${ }^{7}$ The clinical relevance of interactions of buprenorphine with different ORs is not fully resolved but the knowledge on its unique profile is improving with emerging data. Buprenorphine is a potent $\kappa$-receptor antagonist $(\mathrm{Ki}=6 \mathrm{nM})$ and this is believed to resist depression. ${ }^{8,9}$ Buprenorphine acts as a "chaperone" ligand and increases $\mu$-receptor expression on membrane surfaces., ${ }^{2,10,11,12}$ Buprenorphine is also an agonist for nociceptin or OR-like 1 (ORL1) that has a unique interaction with pain processing. Activation of the ORL1 receptor in the dorsal horn is analgesic, but cerebral ORL1 activation blunts antinociception as seen in animal models. ${ }^{12}$ It has been suggested that $\mu$-receptor mediated antinociception can be reduced by the ORL1 agonist activity residing in the same molecule. ${ }^{13,14}$ The relevance of ORL1 activation by buprenorphine under clinical setting is, however, not clear particularly at pharmacological doses to control pain. Additional mechanisms have also been proposed for the analgesic effects of buprenorphine. In interesting studies, peripheral administration of naloxone antagonizes buprenorphine's dose response curve while supraspinal intracerebroventricular (icv) administration of naloxone shows no effect against subcutaneous (sc) administration of buprenorphine in antinociceptive tests. Similarly, icv buprenorphine produces antinociception and intraperitoneal buprenorphine is antagonized by intraperitoneal naloxone, but not by icv naloxone in rat formalin test. ${ }^{15}$ These results suggest a

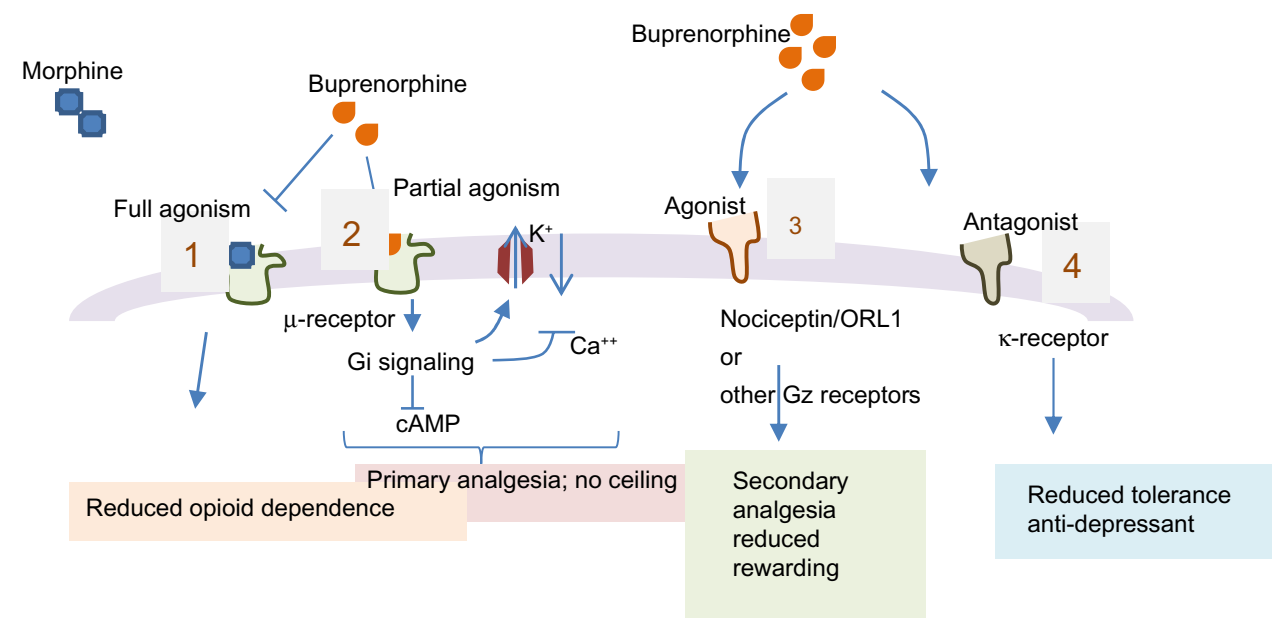

Figure 2 Implications of buprenorphine interactions with opioid receptors. Buprenorphine is a partial and potent agonist of $\mu$-opioid receptor.

Notes: (I) It can displace or block morphine binding to $\mu$-receptor thus contributes to reduced opioid dependence. (2) Buprenorphine agonist activity on $\mu$ receptor is the primary contributing factor to its analgesic signaling events. (3) Buprenorphine interacts with nociceptin/ORLI with much lower affinity and thus is unlikely to contribute to analgesic effects at therapeutic doses. It is conceivable that buprenorphine interactions with other similar receptors could contribute secondary analgesia. (4) Buprenorphine is a potent antagonist of $K$-opioid receptor and this interaction could contribute to reduced tolerance and antidepressant like activity.

Abbreviation: ORLI, opioid receptor-like I. 
Table I Buprenorphine - binding affinity $(\mathrm{Ki}, \mathrm{nM})$ for opioid receptors

\begin{tabular}{lll}
\hline Opioid receptor & Ki $(\mathbf{n M})$ & Agonist/antagonist \\
\hline$\mu$ & 1.5 & Partial agonist \\
$\delta$ & 6.1 & Antagonist \\
$\kappa$ & 2.5 & Antagonist \\
Nociceptin or ORLI & 77.4 & Agonist \\
\hline
\end{tabular}

Abbreviation: ORLI, opioid receptor-like I.

different supraspinal mechanism of action for buprenorphine. Pertussis toxin which prevents ligand-induced activation of G-protein-coupled receptors (GPCRs), antagonizes morphine, and fentanyl but has no effect on buprenorphine mediated analgesia. Further mechanistic studies suggest the involvement of heterotrimeric guanine nucleotide-binding regulatory protein $G_{z}$. Supraspinal administration of $G_{z}$ antisense had no effect on morphine or fentanyl antinociception but blocked buprenorphine effect. The icv administration of okadaic acid (a protein phosphatase inhibitor) blocked buprenorphine but not morphine or fentanyl effect. Thus, supraspinal component of buprenorphine-induced antinociception does not appear to be mediated via the typical $\mu$-opioid response but by other unique receptors. ${ }^{15}$

\section{Pharmacokinetics profile}

Buprenorphine is a lipophilic molecule $(\log \mathrm{P}=4.98)$ with low aqueous solubility. The compound shows high volume of distribution and distributes well in tissues including brain. The protein binding for buprenorphine in human plasma is approximately $96 \%$, not to the albumin but to the $\alpha$ - and $\beta$-globulin fractions. Buprenorphine has very low plasma concentrations and this is not believed to influence competition between globulin binding sites. ${ }^{10}$ Buprenorphine is extensively metabolized in the liver, and the major metabolite norbuprenorphine (Figure 1B) occurs through Cyp3A4 mediated $N$-dealkylation. ${ }^{16,17}$ Both buprenorphine and norbuprenorphine undergo rapid glucuronidation at the phenolic site by UGT2B7 and UGT1A1 in the liver. ${ }^{16,18}$ The plasma levels of conjugate metabolites buprenorphine-3-glucuronide and norbuprenorphine-3-glucuronide can exceed the parent drug levels. In human, norbuprenorphine rarely exceeds $10 \%$ of buprenorphine blood concentrations $\left(\mathrm{C}_{\max }\right) \cdot{ }^{19}$

The relative bioavailability of buprenorphine given intramuscular (im), sublingual solution or sublingual tablet is $70 \%, 49 \%$, and $29 \%$, respectively, assuming $100 \%$ for intravenous (iv) dosing. ${ }^{20-23}$ Sublingual and transdermal formulations tend to show long half-life (20-73 hours). The prolonged terminal half-life of buprenorphine can in part be due to enterohepatic recirculation as observed for nonhuman species. With a sublingual formulation, buprenorphine shows onset of effects at 30-60 minutes postdosing and the peak clinical effects are observed at 1-4 hours. The duration of effect may last for 6-12 hours at low dose $(<4 \mathrm{mg})$ and $24-72$ hours at higher dose $(>16 \mathrm{mg})$. The longer effect at higher buprenorphine sublingual dose may be linked to sustained, effective drug levels for extended duration because of its slower elimination and enterohepatic recirculation (see Table 2 for approved doses of sublingual buprenorphine).

Buprenorphine is eliminated primarily via a stool (as free forms of buprenorphine and norbuprenorphine) while $10 \%-30 \%$ of the dose is excreted in urine as conjugated forms of buprenorphine and norbuprenorphine. Buprenorphine is a preferred opioid for treatment of pain in patients with compromised renal function. Buprenorphine is also safer in patients with a failing liver. ${ }^{24}$

\section{Cyp inhibition and drug-drug interaction potential}

Buprenorphine and its Cyp3A4 mediated metabolite norbuprenorphine are rapidly converted to conjugate. Buprenorphine and norbuprenorphine do not inhibit Cyps at therapeutic doses, and as a result have fewer drug interactions. ${ }^{25}$ Drugs that inhibit Cyp3A4 do not seem to influence the pharmacokinetics (PK) profile of buprenorphine significantly and glucuronidation is generally associated with limited drug interactions. ${ }^{12}$ However, caution should be used when buprenorphine is co-administered with other drugs that inhibit Cyp3A4. The combination of buprenorphine with benzodiazepine or other central nervous system (CNS) depressants should be administered with caution as it may lead to severe or even fatal respiratory depression. ${ }^{26}$

\section{Pharmacology of metabolites}

The reported $\mathrm{K}_{\mathrm{i}}$ values for ORs for buprenorphine and metabolites vary significantly based on the experimental conditions and the laboratories conducting experiments. ${ }^{7,18,27}$ Buprenorphine-3-glucuronide is a $\mu-, \delta$-, and ORL1 agonist, whereas norbuprenorphine-3-glucuronide is a $\kappa$ - and ORL1 ligand. All metabolites except norbuprenorphine-3glucuronide are analgesic and contribute to the observed buprenorphine profile in clinic. ${ }^{18,28}$ Neither buprenorphine nor the glucuronide metabolites reduce respiratory rates, although norbuprenorphine-3-glucuronide has been demonstrated to reduce tidal volume in animal models. ${ }^{18,29}$ 
Table 2 Marketed buprenorphine products

\begin{tabular}{|c|c|c|}
\hline Trade name (product) & $\begin{array}{l}\text { Approval or development status, } \\
\text { ownership }\end{array}$ & Dose form, approved indications \\
\hline Subutex ${ }^{\circledR}$ (Buprenorphine $\mathrm{HCl}$ ) & $\begin{array}{l}\text { - Approved in the US as orphan drug } \\
\text { - Generic since } 2009 \\
\text { - Subutex brand discontinued in } 2011\end{array}$ & $\begin{array}{l}\text { - Sublingual; tablets ( } 2 \text { and } 8 \mathrm{mg} \text { ) } \\
\text { - For treatment of opioid dependence }\end{array}$ \\
\hline Norspan ${ }^{\circledast}$ (Buprenorphine) & $\begin{array}{l}\text { - Approved in } \sim 15 \text { countries in the EU } \\
\text { - Mundipharma, Sydney, Australia }\end{array}$ & $\begin{array}{l}\text { - Transdermal patch }(5,10 \text {, and } 20 \mathrm{ug} / \mathrm{h}) \\
\text { - For treatment of moderate to severe pain }\end{array}$ \\
\hline Butrans $^{\circledR}$ (Buprenorphine) & $\begin{array}{l}\text { - Approved in the US } \\
\text { - Purdue Pharma, Stamford, CT, USA }\end{array}$ & $\begin{array}{l}\text { - Transdermal patch }(7.5,10 \text {, and } 20 \mathrm{ug} / \mathrm{h}) \\
\text { - For moderate to severe pain }\end{array}$ \\
\hline Suboxone ${ }^{\circledast}$ (Bupre + naloxone) & $\begin{array}{l}\text { - Approved in the US as orphan drug } \\
\text { - Generic since } 2009 \\
\text { - Suboxone brand discontinued in } 2012\end{array}$ & $\begin{array}{l}\text { - Sublingual tablets ( } 2 / 0.5 ; 8 / 2 \mathrm{mg} \text { combo) } \\
\text { - For treatment of opioid dependence }\end{array}$ \\
\hline Zubsolv $^{\circledR}$ (Bupre + naloxone) & $\begin{array}{l}\text { - Approved in the US in September } 2013 \\
\text { - Orexo, Uppsala, Sweden }\end{array}$ & $\begin{array}{l}\text { - Sublingual tablets (I.4/0.36; } 5.7 / 1.4 \mathrm{mg}) \\
\text { - For treatment of opioid dependence }\end{array}$ \\
\hline Temgesic $^{\circledR}$ (Bupre) & $\begin{array}{l}\text { - Approved in } \sim 20 \text { countries in the EU } \\
\text { - Reckitt Benckiser Pharmaceuticals Inc., } \\
\text { Richmond, VA, USA }\end{array}$ & $\begin{array}{l}\text { - Sublingual tablets } \\
\text { - For treatment of opioid dependence }\end{array}$ \\
\hline Bunavail $^{\circledast}$ (Bupre + naloxone) & $\begin{array}{l}\text { - Approved in the US in June } 2014 \\
\text { - BioDelivery Sciences, Raleigh, NC, USA }\end{array}$ & $\begin{array}{l}\text { - First mucoadhesive buccal film (2.I/0.3; } \\
4.2 / 0.7 ; 6.3 / \mathrm{I} \mathrm{mg}) \\
\text { - For treatment of opioid dependence }\end{array}$ \\
\hline Buprenex $^{\circledR}$ (Buprenorphine) & $\begin{array}{l}\text { - Approved in the US } \\
\text { - Generic drug } \\
\text { - Reckitt Benckiser Pharmaceuticals Inc. }\end{array}$ & $\begin{array}{l}\text { - Parenteral (iv or im; } 0.3 \mathrm{mg} \text { ) formulation } \\
\text { - For treatment of moderate to severe pain }\end{array}$ \\
\hline
\end{tabular}

Abbreviations: iv, intravenous; im, intramuscular; Bupre, Buprenorphine.

Norbuprenorphine is a potent $\mu$-agonist and contributes to respiratory depression. ${ }^{30}$

\section{Safety of buprenorphine vs other opioids}

The primary side effects of buprenorphine are similar to other $\mu$-opioid agonists (eg, nausea, vomiting, and constipation), but the intensity of these side effects is reduced significantly compared to full agonist. The superiority of buprenorphine over other opioids in safety was recently addressed. ${ }^{12}$

\section{Respiratory depression}

Buprenorphine has a ceiling effect on respiratory depression and remains one of the safest opioids to curtail this adverse effect as concluded by a panel of experts reviewing opioid pharmacology. ${ }^{10,12,31-33}$ Typically, $1 \%-11 \%$ of patients on opioid therapy suffer from respiratory depression that seems to be more pronounced in seniors, obese, or individuals with sleep apnea or neuromuscular disease. Respiratory depression associated with buprenorphine may be partly related to its metabolite, norbuprenorphine, and not to the parent drug. Interestingly, buprenorphine prevents and reverses respiratory depression in rats that are given lethal injections of norbuprenorphine. ${ }^{34}$ In another study, much higher safety window (13.5-fold) is reported for buprenorphine than for fentanyl (1.2-fold) when comparing analgesia and respiratory distress doses in rat. ${ }^{35}$
The combination of buprenorphine with sedative drugs such as benzodiazepine or alcohol has been reported to affect respiratory depression adversely. Buprenorphinebenzodiazepine combination, however, seems safer than methadone-benzodiazepine for respiratory distress. ${ }^{26}$ Caution should, however, be exercised in combination therapy of buprenorphine with CNS depressants.

\section{Constipation}

Based on reported data from clinical studies, buprenorphine exhibits much lower incidence (1\%-5\%) of constipation than observed with full $\mu$-agonists. ${ }^{2,36,37}$ Unlike other opioids, buprenorphine does not cause spasm of the sphincter of Oddi and may be a preferred choice, along with nonsteroidal anti-inflammatory drugs, in the management of biliary colic and/or pancreatitis. ${ }^{38}$

\section{Cognitive and psychomotor effects}

Opioid use can impair cognitive function and driving ability. Addiction to opioids can influence dependability. The addition of alcohol or sedatives may worsen the cognitive and driving ability. Comparative studies done report that buprenorphine may have better visual, psychomotor or cognitive function vs morphine, methadone or fentanyl. ${ }^{12,39}$ In many cases, buprenorphine effect on cognitive and psychomotor function was comparable to placebo. ${ }^{40}$ 


\section{Immunosuppression}

Opioids seem to trigger unique biochemical communication between brain and the immune system. The reported data suggest that while exogenous opioids suppress the immune system, the endogenous opioids stimulate it. The implications of opioid evoked immunosuppression are particularly relevant during the postoperative period when the pain and susceptibility to infection are high; for sufferers of chronic pain who administer opioids for extended periods; and for patients with immunosuppressive disease such as AIDS, transplant patients, and the elderly, who are predisposed to opportunistic infections..$^{41}$ The potent opioids such as morphine and fentanyl reduce antibody production, reduce natural killer cell activity, and impair the cytokine expression and phagocytic activity of white cells. ${ }^{12}$ The immunosuppressive effect is accentuated in presence of corticosteroids or other immunosuppressive drugs. Some immunosuppression in morphine may also emerge through non- $\mu$-receptor mediation as the effect is not reversed by naltrexone. ${ }^{42,43}$ Unlike morphine, buprenorphine does not reduce natural killer-cell function, increase cortisol, reduce adrenocorticotropic hormone levels, or alter norepinephrine or serotonin levels after injection in the brain. Most of the studies showing lack of immunosuppressive effect of buprenorphine have been conducted in animals and their clinical relevance needs to be established. However, in immunosuppressed patients, opioids (morphine, fentanyl) treatment may be avoided and buprenorphine should be considered in the scheme of options..$^{10,12,43-45}$

\section{Hypogonadism}

Chronic use of $\mu$-receptor agonists has been associated with hypogonadism and fatigue. With time, hypogonadism can lead to osteopenia and loss of muscle mass. Use of morphine and fentanyl is reported to reduce testosterone levels and testosterone replacement therapy is often recommended. Even at high doses, buprenorphine seems to have minimal effect on sexual hormone levels. ${ }^{46-49}$

\section{QTc prolongation vs methadone}

Based on reported data, methadone-maintenance treatment has been associated with QTc prolongation (approximately $29 \%$ patients) with approximately $5 \%$ showing QTc interval of $>500 \mathrm{~ms}$. The risk of QTc prolongation seems particularly high at doses of $>120 \mathrm{mg}$. In contrast, buprenorphinemaintenance therapy for opioid dependence does not seem to be associated with QTc prolongation. Torsades de pointes or sudden cardiac deaths occur four times more frequently with methadone than with buprenorphine. ${ }^{50-53}$ All reported
QTc studies on buprenorphine seem to be on opioid maintenance therapy. Since the dose needed for analgesic effect is generally lower, it should also improve therapeutic window for cardiac safety.

\section{Seniors' treatment}

Multiple studies undertaken on elderly patients (age 65 years and above) indicate that PK profile, efficacy results, or adverse events of buprenorphine did not alter with age. Many elderly patients tend to suffer from chronic diseases such as arthritis, diabetes, cardiovascular issues, or cancer. For all opioids except buprenorphine, half-life of the parent drug and its metabolites increased in elderly and those with renal impairment. ${ }^{2,10,54-56}$ For elderly on multiple medications, drug-drug interactions mediated through Cyp enzymes are not uncommon. However, buprenorphine and its Cyp3A4 mediated metabolite are rapidly converted to conjugate. Drugs that inhibit Cyp3A4 do not seem to influence the PK profile of buprenorphine significantly and glucuronidation is generally associated with limited drug interactions. Buprenorphine also seems to be the select opioid that is not associated with fracture in elderly. ${ }^{57}$

\section{Patients with renal failure}

Buprenorphine is largely eliminated through bile in nonrenal pathway. The levels of buprenorphine and its metabolite as well as pain rating do not seem to change for patients on dialysis. ${ }^{58,59}$ The drug is also relatively safe in patients with liver failure. ${ }^{60}$ The data favor selection of buprenorphine as preferred opioid during emergency or intensive care hospitalization.

\section{Tolerance and hyperalgesia}

The clinical usefulness of opioids is often hampered by the development of tolerance after chronic treatment. Although tolerance to the antinociceptive effect of buprenorphine has been demonstrated, the onset is slower than tolerance to morphine. In a retrospective study involving nearly 900 cancer and noncancer patients buprenorphine produced less analgesic tolerance than fentanyl, as measured by an opioid escalation index. ${ }^{61-64}$ Multiple mechanisms have been proposed to explain opioid tolerance observed with $\mu$-agonists such as morphine. ${ }^{2,10}$ Among others, a proposed mechanism of tolerance indicates increased activity of the anti-opiate peptides in the brain (eg, ORL1 ligand Orphanin-FQ/nociceptin (OFQ/N) and dynorphin). Buprenorphine may also control secondary hyperalgesia through activation of ORL1 receptor, antagonism of $\kappa$-receptor ${ }^{62}$ or other pathways. ${ }^{65}$ 


\section{Abuse potential and withdrawal}

Buprenorphine is a partial agonist and has fewer rewarding effects compared to another $\mu$-agonists and blocks psychological dependence. Despite these properties, there have been reports of abuse particularly by new users. ${ }^{66,67}$ To counter potential misuse, a combination of buprenorphine with the opioid antagonist naloxone in a ratio of 4 to 1 , has been used in sublingual administration. Naloxone has poor bioavailability (approximately 3\%) on sublingual dosing. Thus, when the buprenorphine/naloxone tablet is taken in sublingual form, the buprenorphine opioid agonist effect predominates, and the naloxone does not precipitate opioid withdrawal in the opioid-addicted user. Naloxone via the parenteral route, however, has good bioavailability. If the sublingual buprenorphine/naloxone tablets are crushed and injected by an opioid-addicted individual, the naloxone effect predominates and can precipitate the opioid withdrawal syndrome.

Typically, the withdrawal syndrome following the abrupt cessation of long-term buprenorphine treatment emerges within 3-5 days of the last dose, and mild withdrawal features continue for up to several weeks. Treatment with opioid antagonist (naloxone) can be commenced within days of the cessation of low dose buprenorphine treatment without precipitating severe opioid withdrawal. This enables patients to transfer promptly to naloxone treatment, and avoid relapse and treatment drop-out. ${ }^{10}$

A summary of comparative safety profile of buprenorphine with other opioids is captured in Table 3.

\section{Efficacy of buprenorphine Buprenorphine in treatment for opioid dependence}

Buprenorphine has been used extensively for treatment of opioid addiction and this also accounts for a significant portion of its market revenues. The main signs experienced during the initial stages of opioid withdrawal include nausea, vomiting, diaphoresis, yawning, fatigue, aches and pain, diarrhea, mydriasis, and piloerection. Cravings initiate 4-6 hours after the last dose of short-acting and at 12-24 hours after last dose of long-term opioids. This is followed by anxiety, diaphoresis, agitation, and the other symptoms. Peak withdrawal discomfort is usually experienced after 36-72 hours and decreases thereafter. ${ }^{68,69}$ Consciousness is usually unimpaired, and opioid withdrawal is not life threatening, even if untreated in outpatient or inpatient settings. A Cochrane review of 13 studies concluded "buprenorphine is an effective intervention for the treatment of opioid dependence". ${ }^{70}$

Buprenorphine's high binding affinity and low intrinsic activity can induce withdrawal in opioid dependent patients that are using full $\mu$-agonists (methadone, heroin, and morphine) by displacing opioids from the receptor. ${ }^{69,71}$ To control opioid dependence, buprenorphine treatment is initiated at the appearance of withdrawal symptoms. The patients on opioids are encouraged to abstain from use for until at least 12-24 hours or until the emergence of withdrawal symptoms. The patients are started on a low dose of transdermal or sublingual formulation of buprenorphine. If clinical signs remain controlled, buprenorphine is titrated upwards to individualized dose. A small randomized controlled trial $(\mathrm{N}=32)$ showed no significant difference in withdrawal symptoms between buprenorphine and buprenorphine/naloxone. ${ }^{72}$ The consensus panel recommends that buprenorphine/naloxone be used for the induction, stabilization, and maintenance phases of opioid dependence treatment for most patients. For pregnant women, monotherapy of buprenorphine is recommended. In summary, buprenorphine is an effective detoxifying agent for opioid dependence and is equivalent to or better than methadone. ${ }^{70}$ The buprenorphine has also exhibited utility for longer-term opioid maintenance. Its lower abuse potential and good safety profile make it particularly appealing to family physicians.

Table 3 Comparison of safety profile of buprenorphine with other opioids

\begin{tabular}{|c|c|c|c|c|c|c|c|}
\hline Opioid & $\begin{array}{l}\text { GI safety - } \\
\text { constipation }\end{array}$ & $\begin{array}{l}\text { CNS - } \\
\text { sedation }\end{array}$ & $\begin{array}{l}\text { Respiratory } \\
\text { distress }\end{array}$ & $\begin{array}{l}\text { Immuno } \\
\text { suppression }\end{array}$ & Tolerance & $\begin{array}{l}\text { Addiction/ } \\
\text { dependence }\end{array}$ & Hyperalgesia \\
\hline Morphine & ++++ & +++ & ++++ & ++++ & +++ & Yes & Yes \\
\hline Oxycodone & ++++ & ++++ & +++ & - & +++ & Yes & \\
\hline Hydromorphone & & ++++ & ++++ & - & $?$ & Yes & \\
\hline Fentanyl TD & ++ & ++++ & ++++ & ++++ & +++ & & Yes \\
\hline Methadone & & & ++++ & $?$ & $?$ & & \\
\hline Buprenorphine TD/SL & ++ & + & ++ & - & + & Limited & Anti-hyperalgesia \\
\hline
\end{tabular}

Notes: Incidence and severity of effect is represented as: ++++, high; +++, moderately high; ++, moderate; +, mild; ?, unknown. Abbreviations: CNS, central nervous system; GI, gastrointestinal; SL, sublingual; TD, transdermal. 


\section{Buprenorphine in pain treatment}

Buprenorphine is a partial agonist at $\mu$-receptor. The data in Table 1 suggests that the affinity of buprenorphine for ORL1 receptor is approximately 50 times lower than for $\mu$-receptor and many preclinical reports indicate that ORL1 agonism may contribute to reducing its antinociception effect at high concentration. The significance of ORL1 activation and implication on pronociceptive effect are not validated in clinic. ${ }^{10,12,28}$ In addition, a number of studies suggest that buprenorphine dose needs for treatment of pain are much lower compared to doses used for the treatment of opioid addiction. The typical analgesic dose of buprenorphine is $0.3-0.6 \mathrm{mg}$ (im or iv), and its analgesic effects last approximately 6 hours ${ }^{67}$ A review of clinical trials showed that buprenorphine was effective in $25 / 26$ trials. $^{73}$ Contrary to previous concerns, no analgesic ceiling effect and no antagonism on a combination of buprenorphine with pure $\mu$-OR agonists is seen within the therapeutic dose range in humans. ${ }^{12,28}$ Some authors believe that false myths about buprenorphine based on unconfirmed animal data and early clinical research came into textbooks on pharmacology and pain approximately 30 years ago and have been difficult to eradicate. ${ }^{28}$ The fact is that in clinical practice there is no bell-shaped dose-response curve, there is no plateau on the dose-response curve, and there is no antagonist effect from buprenorphine on other $\mu$-opioid agonists. ${ }^{28}$ This was also the conclusion by a panel of world experts convened to review pharmacology of buprenorphine and available evidence. ${ }^{2,10,74}$

Effective long-term pain relief requires sustenance of opioid plasma levels for extended period to prolong duration of analgesic action and reduce potential adverse effects. The introduction of slow release, transdermal drug delivery systems offered a number of advantages. Depending upon the formulation and the pain model, buprenorphine has been reported to be approximately $25-100$ times more potent than morphine. ${ }^{75-78}$ The conversion calculations for buprenorphine to morphine suggest an equipotency ratio of 1:110-1:115 to accomplish the same degree of analgesia. ${ }^{77-80}$

Transdermal buprenorphine product butrans ${ }^{\circledR}(5,10$, and $20 \mu \mathrm{g} / \mathrm{h}$ ) is useful in controlling pain. The published observations suggest that $20 \mu \mathrm{g} / \mathrm{h}$ butrans ${ }^{\circledR}$ may be equivalent to $12-16 \mu \mathrm{g} /$ day sublingual dose. At the same time $5 \mu \mathrm{g} / \mathrm{h}$ dose of buprenorphine may be a high start dose for frail, elderly patients.

\section{Efficacy in moderate to severe pain}

Buprenorphine has been studied for treatment of cancer and noncancer pain in large patients. The reports indicate marked improvement in pain intensity from $62 \mathrm{~mm}$ to $16 \mathrm{~mm}$ in visual analog scale of $0-100(0-$ no pain, 100 - severe pain) over 2-week treatment. A starting buprenorphine dose range of $35-70 \mu \mathrm{g} / \mathrm{h}$; with the majority (74\%) starting at $35 \mu \mathrm{g} / \mathrm{h}$ was preferred using transdermal, sublingual, or parenteral dosing. Studies report good to very good pain relief in $85 \%$ patients and improvement in sleep quality (48\%) with low (3\%) discontinuations. Pain relief with buprenorphine seems equivalent to that of morphine, hydromorphone, oxycodone, fentanyl, and methadone. In opioid naïve patients, low dose $(17 \mu \mathrm{g} / \mathrm{h})$ buprenorphine treatment has been reported to reduce pain intensity and improve quality of life. In a comparative study, transdermal buprenorphine reduced pain intensity to a larger extent (mean difference -16.2 in visual analog scale) compared to morphine with significantly lower adverse events (nausea, constipation, and vomiting) and discontinuations relative to morphine. Another review also indicates that buprenorphine treatment gives equivalent analgesic effect but markedly reduced adverse events and discontinuations relative to fentanyl and morphine. ${ }^{80-82}$

\section{Efficacy in neuropathic pain}

Unlike other $\mu$-agonists, buprenorphine seems to block secondary hyperalgesia from central sensitization in human pain conditions..$^{83}$ Buprenorphine has shown efficacy in neuropathic pain in human studies. ${ }^{84,85}$ In two case studies, buprenorphine gave positive response where transdermal fentanyl failed. ${ }^{63,86}$ In this small patient study, ${ }^{63}$ transdermal buprenorphine vs oral morphine gave equianalgesia of 110:1 to $115: 1$. Similarly, approximately $40 \%$ patients with various central neuropathic syndromes (usually considered refractory to opioid analgesia) responded to buprenorphine starting with a low dose $(8.75 \mu \mathrm{g} / \mathrm{h})$ and titrating escalation. In another double-blind study, buprenorphine (iv) showed efficacy in postthoracotomy pain with high response (69\%) at doses ranging from 35 to $70 \mu \mathrm{g} / \mathrm{h}$. Although there are no randomized clinical trials comparing buprenorphine with other opioids, a consensus panel stated that there is significant evidence that buprenorphine effectively relieves neuropathic pain and offers distinct benefit. ${ }^{10,36,63}$ More studies are needed to compare and define the utility of buprenorphine in different neuropathic syndromes.

\section{Efficacy in broad pain phenotypes}

Preclinical studies establish effectiveness of buprenorphine under varying pain conditions including formalin injection, cold temperature tail flick, and diffuse noxious inhibitory control tests. ${ }^{85}$ Human studies indicate buprenorphine to 
be effective in broader pain conditions (bone pain, heat pain, pain related to nerve growth factor injections, and cold pressor pain) than fentanyl which was effective only in cold pressor pain. Less dramatic differences were reported in another comparative pain study between fentanyl and buprenorphine. ${ }^{87}$ The data, however, support the potential utility of buprenorphine in a range of painful conditions.

Buprenorphine (butrans ${ }^{\circledR}$ or butoxone) has also been used successfully to treat musculoskeletal, visceral, as well as for chronic headaches. Furthermore, possibly because of kappa antagonism, buprenorphine seems to have antidepressive and antianxiety properties, which also helps in pain management. 9

\section{Combination and rotation with opioids}

Recent studies indicate that buprenorphine could be effectively and safely combined with full $\mu$-agonists, and switching between buprenorphine and another opioid provides comparable pain relief using equianalgesic doses.,10,12 The results indicate that adding opioids to patients currently receiving buprenorphine therapy is safe and effective, while the addition of buprenorphine to patients receiving other opioid therapy should be used more cautiously. Buprenorphine has been combined with other opioids (morphine, tramadol) and has demonstrated additivity. In one study, supra-additive analgesia has been reported in combination study of buprenorphine with oxycodone or hydromorphone. Although buprenorphine has demonstrated very high affinity for $\mu$-receptors, it occupies fewer receptors for analgesia, which leads to a significant receptor reserve for other $\mu$-agonists. Buprenorphine increases $\mu$-receptor expression, which allows other $\mu$-agonists to interact with receptors.

Supplemental dosing with an opioid is the main treatment suggested to manage breakthrough pain in cancer patients. Combination of immediate release or iv morphine and a basal analgesic regime of transdermal buprenorphine has been used as an effective and safe treatment. Clinically, the treatment shows an additive analgesic effect, without any safety relevant issues. ${ }^{10,88}$ No cross tolerance was observed during rotation between buprenorphine and fentanyl. ${ }^{10,89}$ Future studies will need to confirm combination therapy and the role of buprenorphine in opioid rotation.

\section{Marketed buprenorphine}

A. Transdermal buprenorphine formulations (butrans ${ }^{\circledR}$ ) have been available in the US since 2011 as 5, 10 and $20 \mu \mathrm{g} / \mathrm{h}$ dose for 7-day delivery patches. Buprenorphine has also been available in most European countries since 2001 as transtec $^{\circledR}$ in $35,52.5$ and $70 \mu \mathrm{g} / \mathrm{h}$ transdermal patches that deliver dose over 96 hours. Transdermal buprenorphine is approved and indicated for the management of moderate to severe chronic pain in patients requiring a continuous, around-the-clock opioid analgesic for an extended period. Transdermal patches show high variability in PK and take approximately 60 hours to reach steady state. Slow onset with transdermal formulations and inability to adjust initial dose levels may limit the utility in some cases. The supplemental addition of immediate release full $\mu$-agonist is used as a co-therapy in many cases. Transdermal patches may also cause erythema and pruritus.

B. Sublingual formulations of buprenorphine are available in the US market as monotherapy (generic subutex ${ }^{\circledR}$; tablet) and a combination therapy of buprenorphine with naloxone (generic suboxone ${ }^{\circledR}$, zubsolv ${ }^{\circledR}$, temgesic ${ }^{\circledR}$, as a tablet or film) for opioid addiction. Reckitt Benckiser Pharmaceuticals Inc., Richmond, VA, USA discontinued distribution of buprenorphine/naloxone sublingual tablets in March 2013, as a result of concerns over accidental or unsupervised pediatric exposure compared to the film formulation. Subutex ${ }^{\circledR}$ was discontinued previously in 2011. Sublingual tablets are very common but can take up to 10 minutes to dissolve. Many suffer from after taste, dissolve time, and dispensing restrictions. Branded formulations such as suboxone sublingual film (Reckitt Benckiser Pharmaceuticals Inc.), bunavail ${ }^{\circledR}$ (BioDelivery Sciences, Raleigh, NC, USA) mucoadhesive film and zubsolv $^{\circledR}$ (Orexo, Uppsala, Sweden) sublingual tablet were launched during 2011-2015. Mucoadhesive film bunavail seems to have much better taste but dissolution time may be higher per individual observations.

C. Buprenex ${ }^{\circledR}$ as an injectable (iv or im) approved in US for moderate pain.

D. No oral buprenorphine product is in the market currently. Low bioavailability (poor absorption, high first pass effect) and uncertainty on GI safety have been limiting factors. Some oral formulations are under investigation (Table 4).

These buprenorphine products are classified as Schedule III controlled. The Tables 2 and 4 gives a summary of marketed and under development buprenorphine formulations.

\section{New buprenorphine products in development pipeline}

Among the investigational drugs, attempts are being made to improve oral delivery with enteric coated (REL 1028) or nanoparticle (NTC 510) formulations. There are also attempts 
Table 4 Buprenorphine products under development

\begin{tabular}{|c|c|c|}
\hline Drug/combination & Development phase (ownership) & Dose form; indication \\
\hline BELBUCA (Bupre) & $\begin{array}{l}\text { - NDA in February } 2015 \\
\text { - BioDelivery Sciences, Raleigh, NC, USA and Endo } \\
\text { Pharmaceuticals Inc., Malvern, PA, USA }\end{array}$ & $\begin{array}{l}\text { - Mucoadhesive buccal film } \\
\text { - Chronic pain treatment }\end{array}$ \\
\hline CAM2038 (Bupre) & $\begin{array}{l}\text { - P-III } \\
\text { - Camurus, Lund, Sweden/Braeburn Pharmaceuticals, } \\
\text { New York, NY, USA }\end{array}$ & $\begin{array}{l}\text { - Once a week or once a month sc delivery } \\
\text { - Opioid addiction }\end{array}$ \\
\hline Probuphine & $\begin{array}{l}\text { - P-III } \\
\text { - Titan Pharmaceuticals, Inc., San Francisco, CA, USA }\end{array}$ & $\begin{array}{l}\text { - Subdermal implant; } 6 \text { months delivery } \\
\text { - Opioid addiction }\end{array}$ \\
\hline NTC-5I0 (NanoBup) (Bupre + naloxone) & $\begin{array}{l}\text { - P-ll } \\
\text { - Nanotherapeutics, Alachua, FL, USA }\end{array}$ & - Oral delivery; claimed to mimic IR profile \\
\hline REL-I028 (BuTab) (Bupre) & $\begin{array}{l}\text { - P-I (CTA) } \\
\text { - Relmada Therapeutics, New York, NY, USA }\end{array}$ & $\begin{array}{l}\text { - Enteric coated oral formulation } \\
\text { - 505(b)(2) path } \\
\text { - Pain and opioid dependence }\end{array}$ \\
\hline ALKS-546I (Bupre + samidorphan) & $\begin{array}{l}\text { - P-III } \\
\text { - Alkermes, Dublin, Ireland }\end{array}$ & $\begin{array}{l}\text { - Treatment for cocaine dependence with } \\
\text { National Institute on Drug Abuse } \\
\text { - Adjunct to antidepressant in treatment } \\
\text { resistant depression }\end{array}$ \\
\hline
\end{tabular}

Abbreviations: sc, subcutaneous; P, Phase; Bupre, Buprenorphine; CTA, Clinical Trial Authorization; NDA, New Drug Application; IR, immediate release.

to deliver once a week/month sc formulation (CAM 2038) and six month subdermal (probuphine) implants.

Probuphine - is an investigational subdermal implant containing buprenorphine $\mathrm{HCl}$ for the long-term maintenance treatment of opioid addiction. The drug being developed by Braeburn Pharmaceuticals, New York, NY, USA/Titan Pharmaceuticals, Inc., San Francisco, CA, USA reported encouraging P-III results for long-term maintenance therapy for opioid addiction. Data from 6-month double-blind, efficacy and safety study suggest the implant to be noninferior to sublingual formulation in efficacy while showing benefits in compliance, misuse and abuse. Titan plans to submit an New Drug Application (NDA) toward the end of 2015.

REL-1028 (BuTab) represents novel oral formulations of modified release buprenorphine, being developed for both chronic pain and opioid dependence indications, is designed to overcome the significant first pass metabolism in the upper gastrointestinal tract to allow for enteric coated oral administration in traditional capsule or tablet form.

NTC-510 (NanoBUP) is being developed by Nanotherapeutics as a combination of buprenorphine and naloxone for oral delivery. It uses a proprietary nanoparticle delivery system as an immediate delivery capsule. In Phase-I, the drug combination is claimed to give $60 \%-70 \%$ relative bioavailability vs sublingual formulation. The investigational drug completed Phase-I studies in 2009/2010 and seem to have been studied in Phase IIa for the treatment of pain following dental surgery of third molars. No results are reported.
Belbuca (BioDelivery Sciences) is a mucoadhesive buccal film undergoing NDA review for treatment of moderate to severe chronic pain.

\section{Summary}

Buprenorphine has unique pharmacology and markedly distinct profile vs other opioids. Data from preclinical and clinical studies establish that buprenorphine carries highly discriminatory profile vs known $\mu$-agonists (morphine, fentanyl, and methadone). Safety of buprenorphine is much superior over the marketed opioids -i) ceiling effect on respiratory depression; much lower risk vs other opioids; ii) lower constipation risk vs other opioids; iii) safest opioid for CNS, immune-suppression issues; iv) anti-hyperalgesic profile and low tolerance issues; v) low clearance through renal path; no clinically relevant changes in patients with renal impairment; vi) safer option for seniors; minimal drug-drug interactions and minimal influence on PK. Buprenorphine continues to be used as an effective treatment for opioid addiction during induction, stabilization, and maintenance phases. The recognition that there is no "ceiling effect" on analgesia and that buprenorphine can be combined with marketed opioids without concerns about withdrawal or precipitation is beginning to help patients suffering from moderate to severe pain. In addition, ability to switch buprenorphine or rotate opioids has added flexibility and options for optimal pain relief. Buprenorphine has demonstrated efficacy and improved therapeutic window in cancer, nonmalignant and neuropathic pain conditions. Given its superior safety and efficacy profile, buprenorphine can now be considered 
as a first line therapy for the treatment of a wide range of chronic pain conditions. Ideal buprenorphine formulations may deliver quick onset and persistent plasma levels for extended duration as mono or combination therapy. New buprenorphine formulations (sc or subdermal implants) for sustained, once a week/month delivery of drug are under investigation. Oral delivery of buprenorphine is challenging but can potentially offer convenience, sustained release, quick onset, and ease of dose adjustments - key needs for patients suffering from cancer, postsurgical or other chronic pain conditions. Since buprenorphine dose needs for pain treatment are relatively low, a combination of innovation and modern delivery technologies is likely to present novel solutions to improve absorption and related issues. The oral delivery can also improve on the limitations of marketed (sublingual and transdermal) options discussed earlier. Learnings from ongoing clinical investigations of oral buprenorphine formulations and continuing research in laboratories is likely to open new avenues. Additional clinical studies will also be needed to expand efficacy, improve compliance, and enhance safety of buprenorphine or its combination partner.

\section{Disclosure}

The authors report no conflict of interest in this work.

\section{References}

1. Fine PG, Miaskowski C, Paice JA. Meeting the challenges in cancer pain management. J Support Oncol. 2004;2(Suppl 4):5-22.

2. Kress HG. Clinical update on the pharmacology, efficacy and safety of transdermal buprenorphine. Eur J Pain. 2009;13:219-230.

3. Breivik H, Collett B, Ventafridda V, Cohen R, Gallacher D. Survey of chronic pain in Europe: prevalence, impact on daily life, and treatment. Eur J Pain. 2006;10:287-333.

4. Portenoy RK, Farrar JT, Backonja MM, Cleeland CS, Yang K, Friedman M, et al. Long term use of controlled-release oxycodone for noncancer pain: results of a 3-year registry study. Clin J Pain. 2007;23:287-299.

5. Sites BD, Beach ML, Davis MA. Increases in the use of prescription opioid analgesics and the lack of improvement in disability metrics among users. Reg Anesth Pain Med. 2014;39(1):6-12.

6. Virk MS, Arttamangkul S, Birdsong WT, Williams JT. Buprenorphine is a weak partial agonist that inhibits opioid receptor desensitization. J Neurosci. 2009;29(22):7341-7348.

7. Khroyan TV, Wu J, Polgar WE, et al. BU08073 a buprenorphine ana$\log$ with partial agonist activity at $\mu$ receptors in vitro but long-lasting opioid antagonist activity in vivo in mice. Br J Pharmacol. 2015;172: $668-680$.

8. Karp JF, Butters MA, Begley AE, et al. Safety, tolerability, and clinical effect of low-dose buprenorphine for treatment-resistant depression in midlife and older adults. J Clin Psychiatry. 2014;75(8):e785-e793.

9. Mello NK, Mendelson JH. Behavioral pharmacology of buprenorphine. Drug Alcohol Depend. 1985;14(3-4):283-303.

10. Pergolizzi J, Böger RH, Budd K, et al. Opioids and the management of chronic severe pain in the elderly: consensus statement of an International Expert Panel with focus on the six clinically most often used World Health Organization Step III opioids (buprenorphine, fentanyl, hydromorphone, methadone, morphine, oxycodone). Pain Pract. 2008;8(4):287-313.
11. Zaki PA, Keith DE Jr, Brine GA, Carroll FI, Evans CJ. Ligandinduced changes in surface mu-opioid receptor number: relationship to G protein activation? J Pharmacol Exp Ther. 2000;292(3): 1127-1134.

12. Davis MP. Twelve reasons for considering buprenorphine as a frontline analgesic in the management of pain. J Support Oncol. 2012; 10(6):209-219

13. Khroyan TV, Polgar WE, Jiang F, Zaveri NT, Toll L. Nociceptin/orphanin FQ receptor activation attenuates antinociception induced by mixed nociceptin/orphanin FQ/mu-opioid receptor agonists. J Pharmacol Exp Ther. 2009;331(3):946-953.

14. Spagnolo B, Calo G, Polgar WE, et al. Activities of mixed NOP and mu-opioid receptor ligands. Br J Pharmacol. 2008;153(3): 609-619.

15. Ding Z, Raffa RB. Zhe Ding and Robert B Raffa. Identification of an additional supraspinal component to the analgesic mechanism of action of buprenorphine. Br J Pharmacol. 2009;157:831-843.

16. Kobayashi K, Yamamoto T, Chiba K, et al. Human buprenorphine N-dealkylation is catalyzed by cytochrome P450 3A4. Drug Metab Dispos. 1998;26:818-821.

17. Iribarne C, Picart D, Dréano Y, Bail JP, Berthou F. Involvement of cytochrome P450 3A4 in N-dealkylation of buprenorphine in human liver microsomes. Life Sci. 1997;60(22):1953-1964.

18. Brown SM, Holtzman M, Kim T, Kharasch E. Buprenorphine metabolites, buprenorphine-3-glucuronide and norbuprenorphine-3-glucuronide, are biologically active. Anesthesiology. 2011;115(6):1251-1260.

19. Huestis MA, Cones EJ, Pirnay SO, Umbricht A, Preston KL. Intravenous buprenorphine and norbuprenorphine pharmacokinetics in humans. Drug Alcohol Depend. 2013;131(3):258-262.

20. Brewster D, Humphrey MJ, Mcleavy MA. Biliary excretion, metabolism and enterohepatic circulation of buprenorphine. Xenobiotica. 1981;11: 189-196.

21. Nath RP, Upton RA, Everhart ET, et al. Buprenorphine pharmacokinetics: relative bioavailability of sublingual tablet and liquid formulations. J Clin Pharmacol. 1999;39(6):619-623.

22. Kuhlman JJ, Lalani S, Magluilo J, et al. Human pharmacokinetics of intravenous, sublingual, and buccal buprenorphine $J$ Anal Toxicol. 1996;20:369-378.

23. Schuh KJ, Johanson CE. Pharmacokinetic comparison of the buprenorphine sublingual liquid and tablet. Drug Alcohol Depend. 1999;56(1):55-60.

24. Ciccozzi A, Angeletti C, Baldascino G, et al. High dose of buprenorphine in terminally ill patient with liver failure: efficacy and tolerability. J Opioid Manag. 2012;8(4):253-259.

25. Zhang W, Ramamoorthy Y, Tyndale RF, Sellers EM. Interaction of buprenorphine and its metabolite norbuprenorphine with cytochromes p450 in vitro. Drug Metab Dispos. 2003;31(6):768-772.

26. McCance-Katz EF, Sullivan LE, Nallani S. Drug interactions of clinical importance among the opioids, methadone and buprenorphine, and other frequently prescribed medications: a review. Am J Addict. 2010;19(1):4-16.

27. Huang P, Kehner GB, Cowan A, Liu-Chen LY. Comparison of pharmacological activities of buprenorphine and norbuprenorphine: norbuprenorphine is a potent opioid agonist. J Pharmacol Exp Ther. 2001;297:688-695.

28. Butler S. Buprenorphine - clinically useful but often misunderstood. Scand J Pain. 2013;4:148-152.

29. Gueye PN, Borron SW, Risede P, et al. Buprenorphine and midazolam act in combination to depress respiration in rats. Toxicol Sci. 2002; 65(1):107-114.

30. Ohtani M, Kotaki H, Nishitateno K, Sawada Y, Iga T. Kinetics of respiratory depression in rats induced by buprenorphine and its metabolite, norbuprenorphine. J Pharmacol Exp Ther. 1997;281(1): 428-433.

31. Dahan A, Aarts L, Smith TW. Incidence, reversal, and prevention of opioid-induced respiratory depression. Anesthesiology. 2010; 112(1):226-238. 
32. Dahan A, Yassen A, Romberg R, et al. Buprenorphine induces ceiling in respiratory depression but not in analgesia. Br J Anaesth. 2006; 96(5):627-632.

33. Nielsen S, Dietze P, Lee N, Dunlop A, Taylor D. Concurrent buprenorphine and benzodiazepines use and self-reported opioid toxicity in opioid substitution treatment. Addiction. 2007;102(4): 616-622.

34. Mégarbane B, Marie N, Pirnay S, et al. Buprenorphine is protective against the depressive effects of norbuprenorphine on ventilation. Toxicol Appl Pharmacol. 2006;212(3):256-267.

35. Yassen A, Olofsen E, Kan J, Dahan A, Danhof M. Pharmacokinetic-pharmacodynamic modeling of the effectiveness and safety of buprenorphine and fentanyl in rats. Pharm Res. 2008;25(1): 183-193.

36. Griessinger N, Sittl R, Likar R. Transdermal buprenorphine in clinical practice - a post-marketing surveillance study of 13,179 patients. Curr Med Res Opin. 2005;21:1147-1156.

37. Shipton EA. Safety and tolerability of buprenorphine. In: Budd K, Raffa R, editors. Buprenorphine - The Unique Opioid Analgesic. Stuttgart: Thieme Verlag KG; 2005:92-101.

38. Cuer JC, Dapoigny M, Ajmi S, et al. Effects of buprenorphine on motor activity of the sphincter of Oddi in man. Eur J Clin Pharmacol. 1989; 36(2):203-204.

39. Soyka M, Hock B, Kagerer S, Lehnert R, Limmer C, Kuefner H. Less impairment on one portion of a driving-relevant psychomotor battery in buprenorphine-maintained than in methadone-maintained patients: results of a randomized clinical trial. J Clin Psychopharmacol. 2005; 25(5):490-493.

40. Shmygalev S, Damm M, Weckbecker K, Berghaus G, Petzke F, Sabatowski R. The impact of long-term maintenance treatment with buprenorphine on complex psychomotor and cognitive function. Drug Alcohol Depend. 2011;117(2-3):190-197.

41. Kapitzke D, Vetter I, Cabot PJ. Endogenous opioid analgesia in peripheral tissues and the clinical implications for pain control. Ther Clin Risk Manag. 2005;1(4):279-297.

42. Vallejo R, de Leon-Casasola O, Benyamin R. Opioid therapy and immunosuppression: a review. Am J Ther. 2004;11(5):354-365.

43. Wang J, Barke RA, Roy S. Transcriptional and epigenetic regulation of interleukin-2 gene in activated T cells by morphine. J Biol Chem. 2007;282(10):7164-7171.

44. Sacerdote P. Opioids and the immune system. Palliat Med. 2006;20 (Suppl 1):S9-S15.

45. Sacerdote P. Opioid-induced immunosuppression. Curr Opin Support Palliat Care. 2008;2(1):14-18.

46. Aloisi AM, Ceccarelli I, Carlucci M, et al. Hormone replacement therapy in morphine-induced hypogonadic male chronic pain patients. Reprod Biol Endocrinol. 2011;9:26.

47. Bliesener N, Albrecht S, Schwager A, Weckbecker K, Lichtermann D, Klingmuller D. Plasma testosterone and sexual function in men receiving buprenorphine maintenance for opioid dependence. J Clin Endocrinol Metab. 2005;90(1):203-206.

48. Hallinan R, Byrne A, Agho K, McMahon CG, Tynan P, Attia J. Hypogonadism in men receiving methadone and buprenorphine maintenance treatment. Int J Androl. 2009;32(2):131-139.

49. Hallinan R, Byrne A, Agho K, McMahon C, Tynan P, Attia J. Erectile dysfunction in men receiving methadone and buprenorphine maintenance treatment. J Sex Med. 2008;5(3):684-692.

50. Krantz MJ, Martin J, Stimmel B, Mehta D, Haigney MC. QTc interval screening in methadone treatment. Ann Intern Med. 2009; 150(6):387-395.

51. Anchersen K, Clausen T, Gossop M, Hansteen V, Waal H. Prevalence and clinical relevance of corrected QT interval prolongation during methadone and buprenorphine treatment: a mortality assessment study. Addiction. 2009;104(6):993-999.

52. Athanasos P, Farquharson AL, Compton P, Psaltis P, Hay J. Electrocardiogram characteristics of methadone and buprenorphine maintained subjects. J Addict Dis. 2008;27(3):31-35.
53. Wedam EF, Bigelow GE, Johnson RE, Nuzzo PA, Haigney MC. QTinterval effects of methadone, levomethadyl, and buprenorphine in a randomized trial. Arch Intern Med. 2007;167(22):2469-2475.

54. Hand CW, Sear JW, Uppington J, Ball MJ, McQuay HJ, Moore RA. Buprenorphine disposition in patients with renal impairment: single and continuous dosing, with special reference to metabolites. Br J Anaesth. 1990;64(3):276-282.

55. Iribarne $\mathrm{C}$, Berthou $\mathrm{F}$, Carlhant D, et al. Inhibition of methadone and buprenorphine N-dealkylations by three HIV-1 protease inhibitors. Drug Metab Dispos. 1998;26(3):257-260.

56. Seripa D, Pilotto A, Panza F, Matera MG, Pilotto A. Pharmacogenetics of cytochrome P450 (CYP) in the elderly. Ageing Res Rev. 2010; 9(4):457-474.

57. Vestergaard P, Rejnmark L, Mosekilde L. Fracture risk associated with the use of morphine and opiates. J Intern Med. 2006;260(1):76-87.

58. Böger RH. Renal impairment: a challenge for opioid treatment? the role of buprenorphine. Palliat Med. 2006;20(Supp1 1):S17-S23.

59. Filitz J, Griessinger N, Sittl R, Likar R, Schuttler J, Koppert W. Effects of intermittent hemodialysis on buprenorphine and norbuprenorphine plasma concentrations in chronic pain patients treated with transdermal buprenorphine. Eur J Pain. 2006;10(8):743-748.

60. Likar R. Transdermal buprenorphine in the management of persistent pain - safety aspects. Ther Clin Risk Manag. 2006;2(1):115-125.

61. Koppert W, Ihmsen H, Korber N, Wehrfritz A, Sittl R, Schmelz M. Different profiles of buprenorphine induced analgesia and antihyperalgesia in a human pain model. Pain. 2005;118:15-22.

62. Vanderah TW, Gardell LR, Burgess SE, et al. Dynorphin promotes abnormal pain and spinal opioid antinociceptive tolerance. J Neurosci. 2000;20:7074-7079.

63. Likar R, Sittl R. Transdermal buprenorphine for treating nociceptive and neuropathic pain: four case studies. Anaesth Analg. 2005;100: 781-785.

64. Louis F. Transdermal buprenorphine in pain management-experiences from clinical practice: five case studies. Int J Clin Pract. 2006; 60(10):1330-1334.

65. Lutfy K, Cowan A. Buprenorphine: a unique drug with complex pharmacology. Curr Neuropharmacol. 2004;2(4):395-402.

66. Walsh SL, Eissenberg T. The clinical pharmacology of buprenorphine: extrapolating from the laboratory to the clinic. Drug Alcohol Depend. 2003;70(Suppl 2):S13-S27.

67. McNicholas L. Clinical Guidelines for the Use of Buprenorphine in the Treatment of Opioid Addiction. A Treatment Improvement Protocol TIP 40; Rockville, MD: US Department of Health and Human Services. DHHS Publication No. (SMA) 04-3939 2004:1-147.

68. Farrell M. Opiate withdrawal. Addiction. 1994;89(11):1471-1475.

69. Ducharme S, Fraser R, Gill K. Update on the clinical use of buprenorphine: in opioid-related disorders. Can Fam Physician. 2012;58: 37-41.

70. Gowing L, Ali R, White J. Buprenorphine for the management of opioid withdrawal. Cochrane Database Syst Rev. 2006;(2):CD002025.

71. Strain EC, Preston KL, Liebson IA, Bigelow GE. Buprenorphine effects in methadone-maintained volunteers: effects at two hours after methadone. J Pharmacol Exp Ther. 1995;272(2):628-638.

72. Strain EC, Harrison JA, Bigelow GE. Induction of opioid-dependent individuals onto buprenorphine and buprenorphine/naloxone solublefilms. Clin Pharmacol Ther. 2011;89(3):443-449.

73. Raffa RB, Haidery M, Huang HM, et al. The clinical analgesic efficacy of buprenorphine. J Clin Pharm Ther. 2014;39(6):577-583.

74. Pergolizzi J, Aloisi AM, Dahan A, et al. Current knowledge of buprenorphine and its unique pharmacological profile. Pain Pract. 2010;10(5):428-450.

75. Atkinson RE, Schofield P, Mellor P. The efficacy in sequential use of buprenorphine and morphine in advanced cancer pain. In: Doyle D, editor. Opioids in the Treatment of Cancer Pain. International Congress and Symposium Series. London: Royal Society of Medicine Services. 1990;146:81-87.

76. Jasinski DR, Pevnick JS, Griffith JD. Human pharmacology and abuse potential of the analgesic buprenorphine: a potential agent for treating narcotic addiction. Arch Gen Psychiatry. 1978;35(4):501-516. 
77. Sittl R, Likar R, Poulsen-Nautrup B. Equipotent doses of transdermal fentanyl and transdermal buprenorphine in patients with cancer and non-cancer pain: results of a retrospective cohort study. Clin Ther. 2005;27:225-237.

78. Sittl R. Transdermal buprenorphine in clinical practice. In: Budd K, Raffa R, editors. Buprenorphine - The Unique Opioid Analgesic. Stuttgart: Thieme Verlag KG; 2005:92-101.

79. Sittl R. Transdermal buprenorphine in cancer pain and palliative care. Palliat Med. 2006;20(Supp 1):s25-s30.

80. Böhme K, Likar R. Efficacy and tolerability of a new opioid analgesic formulation, buprenorphine transdermal therapeutic system (TDS), in the treatment of patients with chronic pain. A randomised, double-blind, placebo-controlled study. Pain Clinic. 2003;15(2):193-202.

81. Sittl R, Griessinger N, Likar R. Analgesic efficacy and tolerability of transdermal buprenorphine in patients with inadequately controlled chronic pain related to cancer and other disorders: A multicenter randomized, double-blind, placebo-controlled study. Clin Ther. 2003;25(1):150-168.

82. Sorge J, Sittl R. Transdermal buprenorphine in the treatment of chronic pain: Results of a phase III, multicenter, randomized, double-blind, placebo-controlled study. Clin Ther. 2004;26(11):1808-1820.
83. Induru RR, Davis MP. Buprenorphine for neuropathic pain - targeting hyperalgesia. Am J Hosp Palliat Care. 2009;26(6):470-473.

84. Benedetti F. Dose-response relationship of opioids in nociceptive and neuropathic postoperative pain. Pain. 1998;74:205-211.

85. Hans G. Buprenorphine - a review of its role in neuropathic pain. J Opioid Manag. 2007;3(4):195-206.

86. Andresen, T, Staahl C, Oksche A, Mansikka H, Arendt-Nielsen L, Drewes AM. Effect of transdermal opioids in experimentally induced superficial, deep and hyperalgesic pain. Br J Pharmacol. 2011;164:934-945.

87. Wolff RF, Aune D, Truyers C, Hernandez AV,Misso K, Riemsma R, Kleijnen J Systematic review of efficacy and safety of buprenorphine versus fentanyl or morphine in patients with chronic moderate to severe pain. Curr Med Res Opin. 2012;28(5):833-845.

88. Mercadante S, Villari P, Ferrera P, et al. Safety and effectiveness of intravenous morphine for episodic breakthrough pain in patients receiving transdermal buprenorphine. J Pain Symptom Manage. 2006;32: 175-179.

89. Cowan A, Friderichs E, Straßburger W, Raffa RB. Basic pharmacology of buprenorphine. In: Budd K, Raffa RB, editors. Buprenorphine-The Unique Opioid Analgesic. Stuttgart: Thieme Verlag KG. 2005, 92-101.
Journal of Pain Research

\section{Publish your work in this journal}

The Journal of Pain Research is an international, peer-reviewed, open access, online journal that welcomes laboratory and clinical findings in the fields of pain research and the prevention and management of pain. Original research, reviews, symposium reports, hypothesis formation and commentaries are all considered for publication.

\section{Dovepress}

The manuscript management system is completely online and includes a very quick and fair peer-review system, which is all easy to use. Visit http://www.dovepress.com/testimonials.php to read real quotes from published authors. 